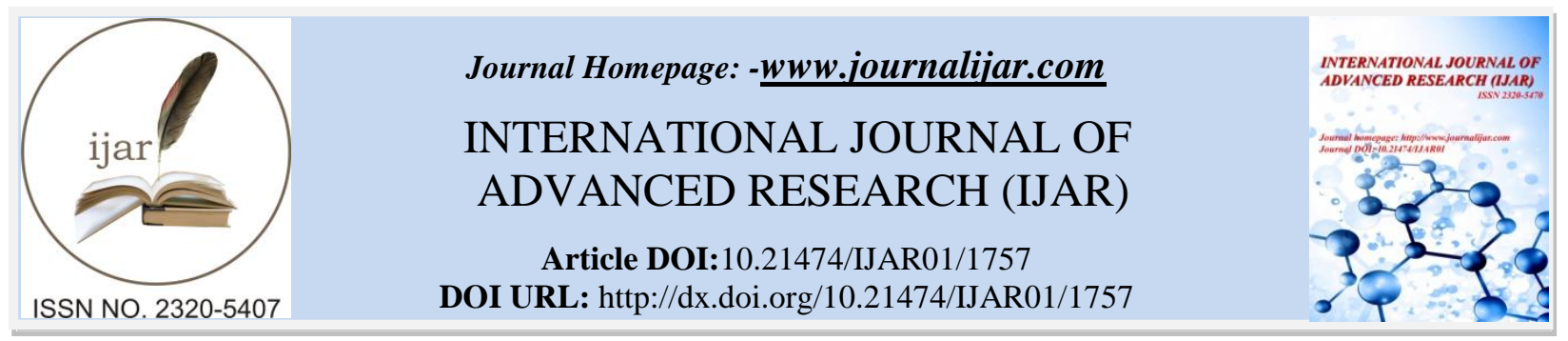

RESEARCH ARTICLE

\title{
THE EFFECTS OF GASEOUS OZONE TREATMENT ON THE SAFETY AND SHELF LIFE OF BERRIES.
}

Maria Paola Previdi ${ }^{1}$, Rita Fiori ${ }^{2}$, Nicolo Dallacasa ${ }^{3}$, Gabriele Fortini ${ }^{1}$ and Barbara Franceschini ${ }^{1}$ *.

1. Stazione Sperimentale per l'Industria delle Conserve Alimentari, SSICA, Viale F. Tanara, 31/A, 43121 Parma, Italy.

2. Via IX Luglio, 4243040 Varano dè Melegari (PR).

3. Via Ugo la Malfa 8, 43123 Parma.

\section{Manuscript Info}

Abstract

Manuscript History

Received: 12 August 2016

Final Accepted: 22 September 2016

Published: October 2016

Copy Right, IJAR, 2016,. All rights reserved.

\section{Introduction:-}

Berries are a perishable food and can be consumed fresh or minimally processed. Berries can alsobe a frozen ingredient in many food products and preparations.Because berries are pulpy fruits with a soft skin and high moisture and sugar contents, they are susceptible to physical damage that accelerates their deterioration by increasing water loss, which can increase microbial contamination (EFSA 2014). These fruits are generally not washed or blanched before selling so there is a microbiological safety risk; several recent cases of infections and poisonings occurred as a result of microbial contamination (Palumbo et al. 2013; ECDC 2014; EFSA 2014). Moreover, berries also have a short shelf-life due to fungal growth. Hence, there is a need for effective methods to prevent spoilage and microbial contamination offresh berries. Ozone gas could be a potential treatment. This gas is a potent sanitizer that is effective against a wide range of microorganisms (Khadreet al. 2001).Moreover, ozone gas is an unstable compound that decomposes rapidly into oxygen without leaving residues, as may occur with chlorine derivatives. Chlorine can form toxic or carcinogenic chlorinated organic compounds that requires that the productbe rinsed, in addition to proper wastewater disposal (Kim et al. 2003; Xu Liangji 1999; Karaka H. and Velioglu Y.S. 2007, Concha-Meyer et al. 2014).

The objective of the present study was to evaluate the effects of a high concentration of gaseous ozone on the microbiological quality of blackberries and blueberries and on the survival of pathogenic microorganisms, such as Listeria innocua (non-pathogenic indicator for L. monocytogenes) and Escherichia coli that can contaminate these berries. Moreover, the effect of low concentrations of gaseous ozone to increase the shelf life of refrigerated berries was also tested.

\section{Materials and methods:-}

Berries:-

Fresh blueberries and blackberries were purchased from local markets.

\section{CorrespondingAuthor:- Barbara Franceschini.}




\section{Gaseous ozonation systems:-}

Ozone gas was generated using an ozone generator (Model Water Proof - MET s.r.l., Bologna, Italy)that produces ozone $(16 \mathrm{~g} / \mathrm{h})$ from purified and concentrated ambient air $\left(98 \% \mathrm{O}_{2}\right)$. The ozone concentration was checked using an ultraviolet ozone analyser (Model GM6000RTI, Anseros Company, Tübingen, Germany). The ozone gasthat was produced was delivered at a flow rate of $7 \mathrm{~L} / \mathrm{min}$.

Tests at high ozone gas concentrationswere carried outin a Plexiglas chamber equipped with a fan to homogeneously diffuse gaseous ozone. The ozone gas concentration was monitored and controlled using a chemical detector (Model Regulator 100 ppm, MET Company s.r.1., Bologna, Italy).

Tests at low ozone gas concentrations were carried out in a refrigeratorequipped with an ozone gas generator (Model $200 \mathrm{mg} / \mathrm{h}$, Mosquito, MET Company s.r.l. Bologna Italy). For the control condition, an identical refrigerator without an ozone gas generator was used. Trials were carried out in high humidity $(\mathrm{RH}>90 \%)$ that was checked using a hygrometer (Model 174H, Testo Spa, Milano, Italy).

\section{Microorganisms and sample inoculation:-}

The following microorganisms were used for berry contamination:

* Escherichia coli SSICA E21 from freshmeat

* Escherichia coli ATCC 25922 from clinical isolate

* Listeria innocua ATCC 33090 from cow brain

* Listeriainnocua SSICA F1 from frozen mushrooms

* ListeriainnocuaSSICA 8 from frozen peas

The microorganisms were cultured at $37^{\circ} \mathrm{C}$ for $24 \mathrm{~h}$ in Brain Heart Infusion (BHI, Oxoid, Basingstoke, UK).

A mixture of L.innocua or E.coli strainswas prepared by combining $2 \mathrm{ml}$ of each culture, washing by centrifugation at $4000 \mathrm{rpm}$ for 10 minutes (Model Megafuge 11R, AhsiS.p.a., Milano, Italy) and suspending the mixture in a saline solution.

To inoculate the berry samples (30 g), $150 \mu \mathrm{l}$ of the microorganism suspensionswere depositedas a droplet on the skin of the berries. The berries were left in a laminar flow cabinet for 1-2 hours in order to allow the microorganisms to attach. The concentration of both bacterial species ranged from $10^{4}$ to $10^{5} \mathrm{cfu} / \mathrm{g}$.

\section{Ozone gas treatments:-}

Gaseous ozone treatments at room temperature $(100 \mathrm{ppm})$ :-

To evaluate the effects of 100 ppmozone gas treatment on native microflora, samples of blackberries and blueberries $(50 \mathrm{~g})$ were transferred toaluminium-perforated baskets and placed in a Plexiglas chamber equipped with an ozone gas generator. The exposure times were 15, 30, 60 and 90 minutes. Tests were performed in triplicates at room temperature.

In the evaluation test on pathogen survival, the same ozone gas concentration was tested against L. innocua and E.coli mixtures that were used to contaminate the $30 \mathrm{~g}$ berry samples. The samples were treated for 15 and 30 minutes.

\section{Gaseous ozone treatments at low temperatures $(0.3 \mathrm{ppm}$ and $1 \mathrm{ppm})$ :-}

Each sample of blackberries and blueberries ( $50 \mathrm{~g})$ was placed in an open plastic basket and stored in the refrigerator with continuous ozone gas exposure. For comparison, other fruit samples were placed in an identical refrigerator without ozonegas exposure. At increasing exposure times, samples were collected from therefrigerators and analysed. Tests were carried out in triplicate under two different conditions: $0.3 \mathrm{ppm}$ at $4^{\circ} \mathrm{C}$ for up to 20 days and 1 ppm at $8^{\circ} \mathrm{C}$ for up to 7 days.

For the test on pathogen survival, treatments with 1 ppmozone gas at $8^{\circ} \mathrm{C}$ were also carried out on $30 \mathrm{~g}$ berry samples that were inoculated with L. innocua and E. coli mixtures. After 24, 48 and 72 h exposure times, three samples from each refrigerator were collected and counted.

\section{Microbiological analysis:-}

Treated berries $(30 \mathrm{~g})$ were placed in a sterile-filtered stomacher bag and diluted to 1:10inbuffered peptone water (ISO - APT). Microbial counts were performed using a plate count technique on the Listeria Oxford Agar Base 
(MOX) for L. innocua $\left(37^{\circ} \mathrm{C}\right.$ for $\left.48 \mathrm{~h}\right)$, TBX medium for E. coli $\left(44^{\circ} \mathrm{C}\right.$ for $\left.24 \mathrm{~h}\right)$, and Malt Extract Agar (MEA acidified to $\mathrm{pH}=4.0$ with citric acid $50 \% \mathrm{w} / \mathrm{w})$ for yeast and mould $\left(25^{\circ} \mathrm{C}\right.$ for 5 days $)$. All media were purchasedfrom Oxoid (Basingstoke, England).

\section{Statistical analysis:-}

Microbial counts were transformed to logarithms before means and standard deviations were computed, and counts were reported as Log cfu/g. The statistical elaboration of the results was performed using SPPSS 13.0.

\section{Results and Discussion:-}

The microbial population on berries mainly consists of yeast and mould, so the effects of gaseous ozone on these microorganisms were tested.

Yeast and mould populations resulted in floating, especially on blackberries. Sometimes a high mould concentration $\left(10^{5} \mathrm{cfu} / \mathrm{g}\right)$ together with a low yeast concentration (it was not possible to enumerate the yeasts because of overgrowth of MEA plates by moulds) was found. At other times, the latter microorganisms were predominantly expressed. In blueberries, both fungi were detected at concentrations between $10^{3}$ and $10^{4} \mathrm{cfu} / \mathrm{g}$.

Microbial concentrations were correlated with the ripeness and integrity of the fruit. In fact, lower consistency, bruising and mechanical damage increase microbial proliferation (EFSA 2014).

\section{Gaseous ozone treatments at room temperature $(100 \mathrm{ppm})$ :-}

The results of these trials were carried out with a high ozone gas concentration, as shown in Table 1 . Treatment with a 100ppm ozone gas concentration for 15 minutes resulted in less than 1Log reduction for yeast and mould, on both blueberries and blackberries. When the treatment timewas increasedto up to 30 minutes, a 1.5 Log reductionwas observed for mould on both berries and for yeast on blueberries.

A further increase in treatment time $(60 \mathrm{~min})$ did not significantly affect microbial population reduction. A 90 minute treatment time resulted in a2Log reduction in mould on both berries, while no significant differences were observed for yeast on blueberries compared to the 30 minutes treatments.

The results indicated that a 30-minutes treatment improves the microbiological quality of fresh blueberries and blackberries, a treatment time suitable for production requirements.

\section{Gaseous ozone treatments at low temperature (0.3 ppm and $1 \mathrm{ppm})$ :-}

The results of trials with low ozone gas concentrations are shown in Figures 1 and 2.

For the trials carried out at $4{ }^{\circ} \mathrm{C}$ with $0.3 \mathrm{ppm}$ of ozone gas, the continuous ozone gas exposure did not significantly affect fungi concentration within twenty days of storage in both berries. A slight increase in the mould concentration in blueberries stored without ozone gas was observed, while the yeast concentration did not significantly change.

Barth et al. (1995) reported that a continuous exposure of blackberries to 0.3 -ppm ozone at $2^{\circ} \mathrm{C}$ for 12 days inhibited fungal development, while $20 \%$ of control fruits showed decay. Palou et al. (2002) observed that continuous exposure to ozone at a concentration of $0.3 \mathrm{ppm}$ for 4 weeks at $5^{\circ} \mathrm{C}$, inhibited the growth of mould on "Elegant Lady" peaches; however, aerial growth and sporulation resumed in ambient atmospheres.

In the present study, the trials carried out at $8^{\circ} \mathrm{C}$ with $1 \mathrm{ppm}$ ozone gas exposure to both berries, did not change the fungi concentration after 7 days of storage.

The slight variations in fungi population observed during storage were probably due to different contamination rates of fruits, as seen by the high standard deviation values.

\section{Pathogen inactivation:-}

Trials were carried out using a mixture of three L. innocua strains (gram-positive bacteria) and another mixture of two E. coli strains (gram-negative bacteria); 
L.innocuawas chosen as a non-pathogenic indicator of L. monocytogenes due to its phylogenetic proximity(Fan et al. 2007; Fairchild and Foegeding 1993).

According to the Regulation EC No.2073/2005 on microbiological criteria for foodstuffs, berries are considered 'ready-to-eat' do not allow the growth of L. monocytogenes(due to their low $\mathrm{pH}$ ). Thus, its concentration during the shelf life of berries must be less than $100 \mathrm{cfu} / \mathrm{g}$.

E. coli is commonly present in faecal material and is widely used as a hygiene indicator. The hygienic microbial criteria for E.coli in 'ready-to-eat' pre-cut fruits and vegetables are between 100 and $1000 \mathrm{cfu} / \mathrm{g}$ (Regulation EC No. 2073/2005).

\section{0ppmozone gas treatment:-}

The efficacy of $100 \mathrm{ppm}$ gaseous ozone treatment on reducing contamination from theL.innocua and E.colimixture was comparable to that observed on the native microflora in berries.

A 15-minutes treatment resulted in a slight reduction of both L.innocuaand E.coliinoculation on blackberries and blueberries. A 30-minutes treatment resulted inmore than one logarithmic decrease (ranged from 1.22 to 1.85 log reductions) on both fruits (Table 2).

In a previous study (Previdi et al.2011) it was observed that ozone gas dissolved in sanitizing water was more effective against inoculated cells than native microorganisms.

Native microbiotaare mainly comprisedof fungi and eukaryotic cellsthat provide defence mechanisms, such as the production of waxy cuticles, biofilm formation. These cells can be protectedby cracks or cuts on fruits. The artificially inoculated bacteria, (prokaryotic and much more simple cells), that underwent to ozone gas exposure for 1-2 hours after inoculation, could presumably have lower chances to stick to a substrate; in the present study, gaseous ozone treatment resulted in the same degree of microbial inactivation.

The decimal reductions achieved in the present study were lower than those reported by Bermúdez-Aguirre et al. (2013), where more than 2Log reductions were obtained on tomatoes artificially inoculated with E. coli and treated for 3 minutes with 5 ppm of ozone gas. However, the same treatment on carrots and lettuce achieved less than 1Log reduction compared to the aforementioned microorganism.

Alwiet al. (2014) treated chili peppers inoculated with E. coli O157: H7,L. monocytogenes and Salmonella entericaTyphimurium with five ozone gas concentrations (1, 3, 5, 7 and $9 \mathrm{ppm}$ ) and increasing exposure times (from 30 minutes to $24 \mathrm{~h})$. The highest death rates were obtained with 9 ppm ozone gas treatment for $6 \mathrm{~h}(2.89,2.56$ and 3.06 logarithmic reductions for E. coli O157: H7, Salmonella Typhimurium and L. monocytogenes population, respectively).

In literature it wasreported that the higher resistance observed in Gram-negative bacteria could be due to a high phospholipid content, which results in increased cell wall rigidity, and provides extra protection for the cell membrane against ozone gas. Despite the presence of a peptidoglycan layer in L. monocytogenes cell walls, this Gram-positive bacterium proved to be very susceptible to ozone gastreatment (Alwiet al. 2014).

\section{1 ppmozone gas treatments:-}

The efficacy of 1ppmgaseous ozone in reducing the population of L. innocuaand E.coli inoculated on berries that were stored at $8^{\circ} \mathrm{C}$ are shown in Figures 3 and 4 .

Within three days of storage, ozone gas treatment reduced L. innocua population by 3logarithms in blackberries and 1.88 logarithms in blueberries compared to time zero. Additionally, 1.88 and 1.29 logarithm reductions in blackberries and blueberries, respectively, were observed, compared to the inoculated, untreated samples.

Concha-Meyer et al. (2014) studied the survival of L.monocytogenes in fresh blueberries stored at $4^{\circ} \mathrm{C}$ with 4ppmozone gas and at $12^{\circ} \mathrm{C}$ with $2.5-\mathrm{ppm}$ of ozone gas: the ozone gas treatments achieved 3 and 2 logarithm reductions, respectively, when compared with air treatment.

In the present study, we observed that storage for several days in the refrigerated condition in the presence of 1 ppm of ozone gas, maintained good sanitizing action against Listeria. 
Exposure to $1 \mathrm{ppm}$ of gaseous ozone at $8^{\circ} \mathrm{C}$ on the inoculated fruits with $E$. coliresulted in no significant differences between treated and untreated fruits after three days of storage (Figure 4).

Table 1:-Log reductions of yeasts and moldson blackberries and blueberries after treatment with 100-ppm gaseous ozone (experiments were replicated three timeswith triplicate determination per experiment; data are expressed as Log cfu/g \pm standard deviation).

\begin{tabular}{|c|c|c|c|c|}
\hline $\begin{array}{c}\text { Exposure time } \\
\text { (minutes) }\end{array}$ & \multicolumn{2}{|c|}{ Blackberries } & \multicolumn{2}{c|}{ Blueberries } \\
\cline { 2 - 5 } & Yeasts & Molds & Yeasts & Molds \\
\hline $\mathbf{1 5}$ & $0.91 \pm 0.21$ & $0.76 \pm 0.21$ & $0.78 \pm 0.17$ & $0.92 \pm 0.18$ \\
\hline $\mathbf{3 0}$ & $1.04 \pm 0.15$ & $1.56 \pm 0.63$ & $1.43 \pm 0.73$ & $1.46 \pm 0.56$ \\
\hline $\mathbf{6 0}$ & $0.78 \pm 0.36$ & $1.67 \pm 0.48$ & $1.20 \pm 0.54$ & $1.92 \pm 0.94$ \\
\hline $\mathbf{9 0}$ & nd & $1.81 \pm 0.61$ & $1.46 \pm 0.85$ & $2.12 \pm 0.52$ \\
\hline
\end{tabular}

nd= not detected.

Table 2:- Log reductions ofL.innocua andE. coli on blackberries and blueberries after treatment with 100-ppm gaseous ozone (experiments were replicated three timeswith triplicate determination per experiment; data are expressed as Log cfu/g \pm standard deviation).

\begin{tabular}{|c|c|c|c|c|}
\hline \multirow{2}{*}{$\begin{array}{c}\text { Exposure time } \\
\text { (minutes) }\end{array}$} & \multicolumn{2}{|c|}{ Blackberries } & \multicolumn{2}{c|}{ Blueberries } \\
\cline { 2 - 5 } & L.innocua & E. coli & L.innocua & E. coli \\
\hline $\mathbf{1 5}$ & $0.71 \pm 0.40$ & $0.54 \pm 0.52$ & $0.26 \pm 0.16$ & $0.47 \pm 0.31$ \\
\hline $\mathbf{3 0}$ & $1.85 \pm 0.74$ & $1.22 \pm 0.36$ & $1.38 \pm 0.31$ & $1.25 \pm 0.39$ \\
\hline
\end{tabular}

Figure 1: Effect of gaseous ozone ( $0.3 \mathrm{ppm})$ on populationsof yeasts and molds in blackberries and blueberries during twenty days storage at $4^{\circ} \mathrm{C}$. Error bars represent $95 \%$ confidence limits $(n=3)$.

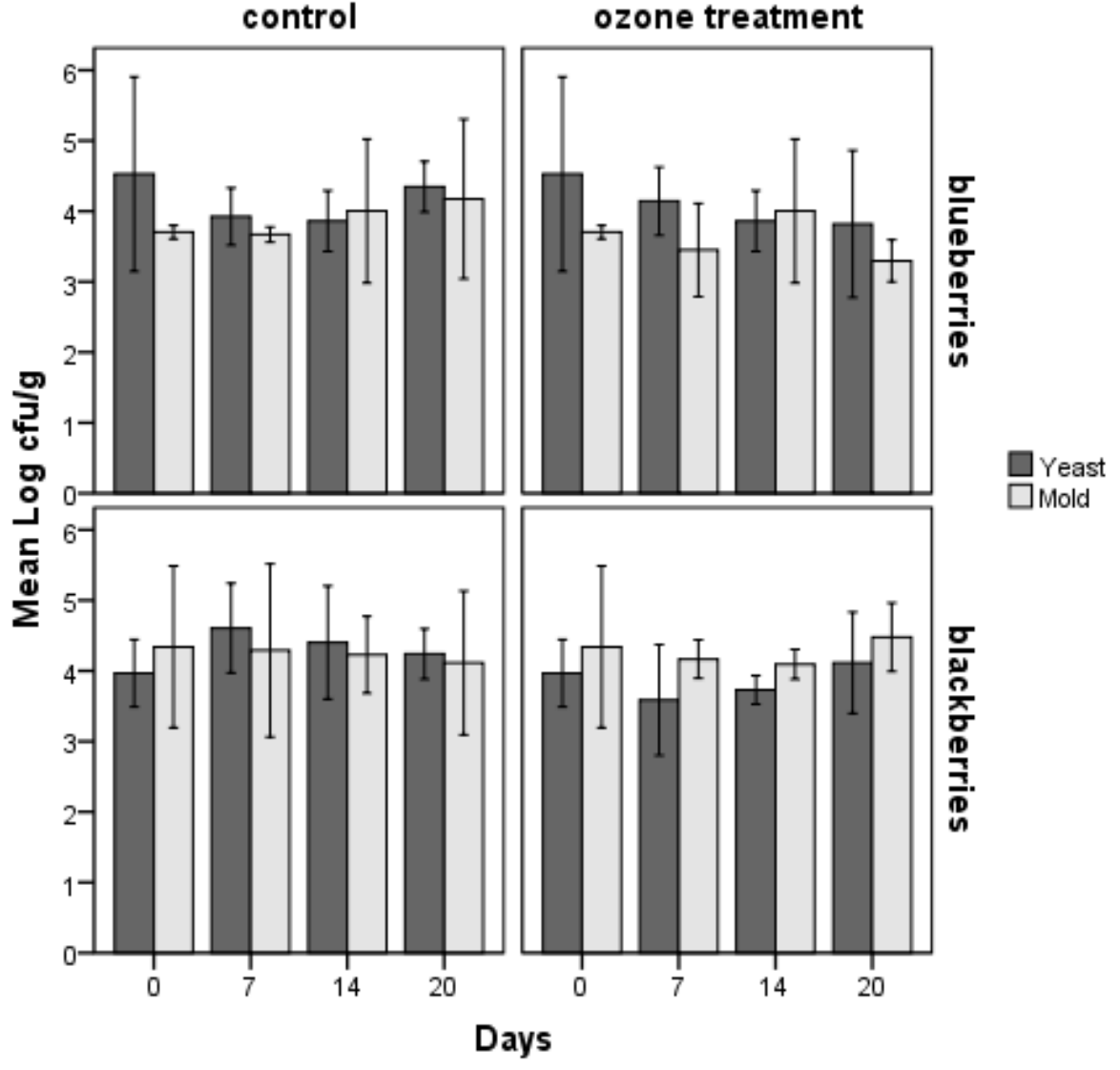


Figure 2:-Effect of gaseous ozone (1 ppm) on populationsof yeasts and moldson blackberries and blueberries during seven days storage at $8^{\circ} \mathrm{C}$. Error bars represent $95 \%$ confidence limits $(n=3)$.

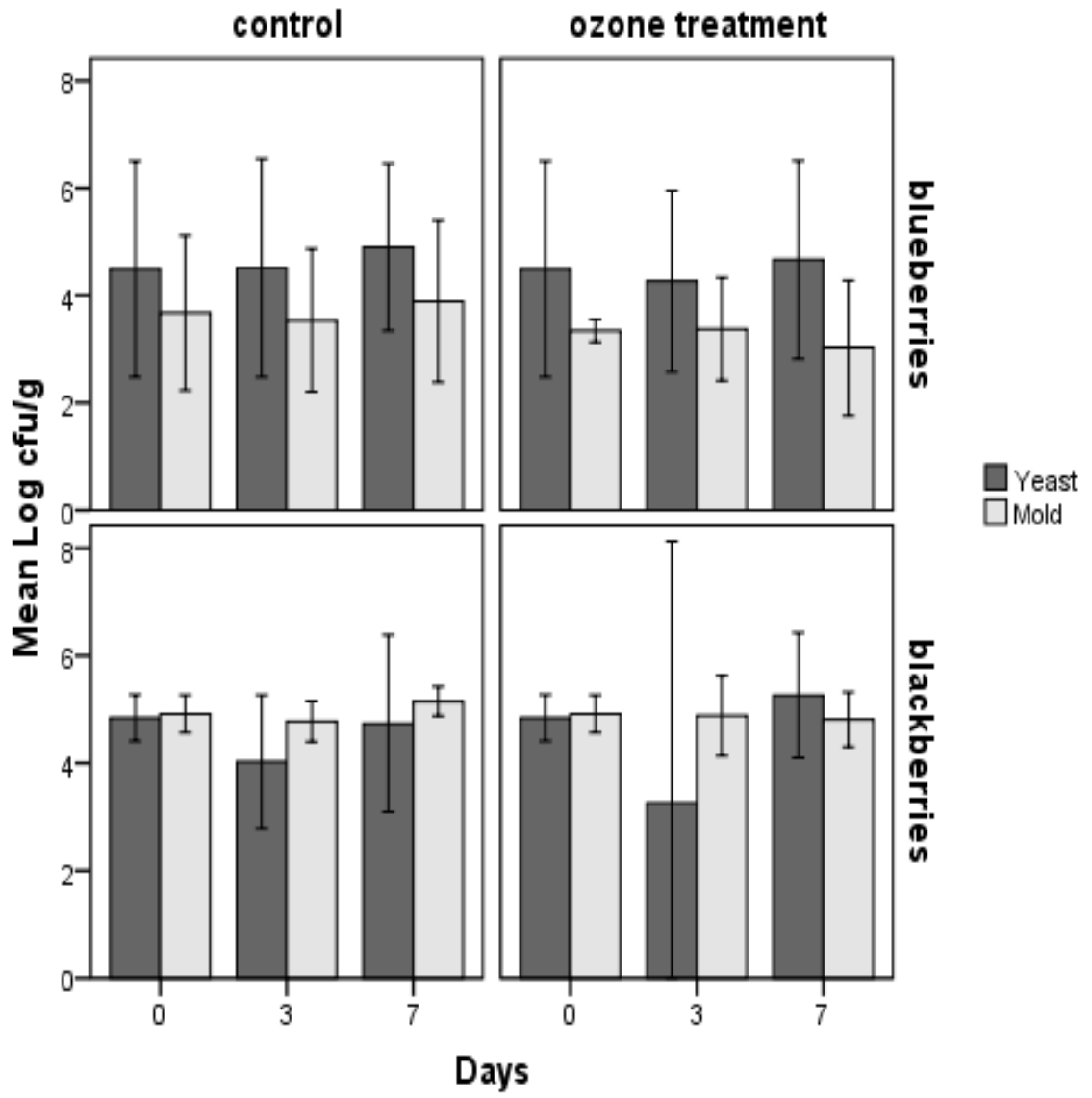


Figure 3:-Effect of gaseous ozone (1 ppm) on Listeria innocuamixture inoculated on blackberries and blueberries during three days storage at $8^{\circ} \mathrm{C}$. Error bars represent $95 \%$ confidence limits $(n=3)$.

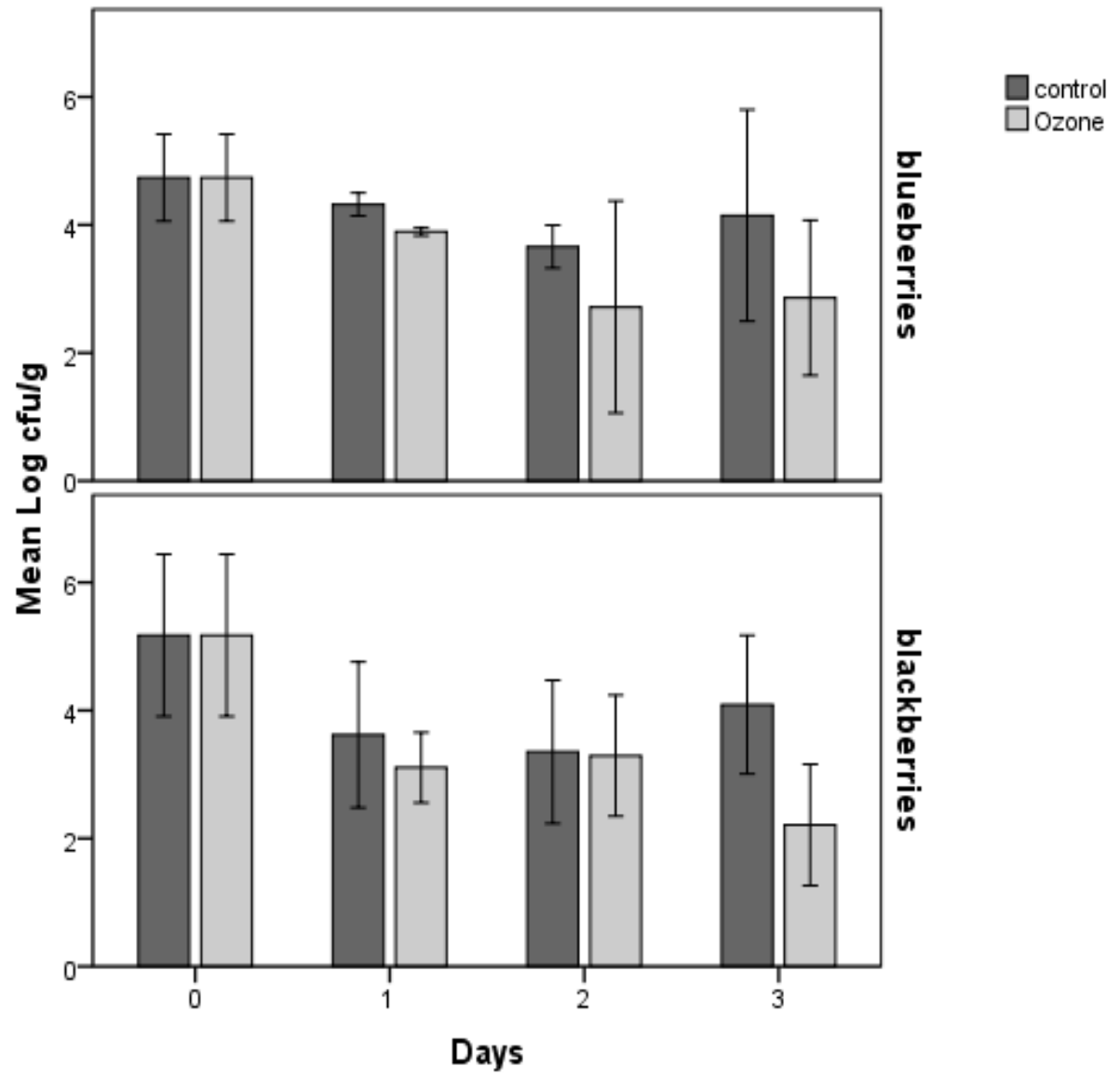


Figure 4:- Effect of gaseous ozone ( $1 \mathrm{ppm})$ on $E$. coli mixture inoculated on blackberries and blueberries during three days storage at $8^{\circ} \mathrm{C}$. Error bars represent $95 \%$ confidence limits $(n=3)$.

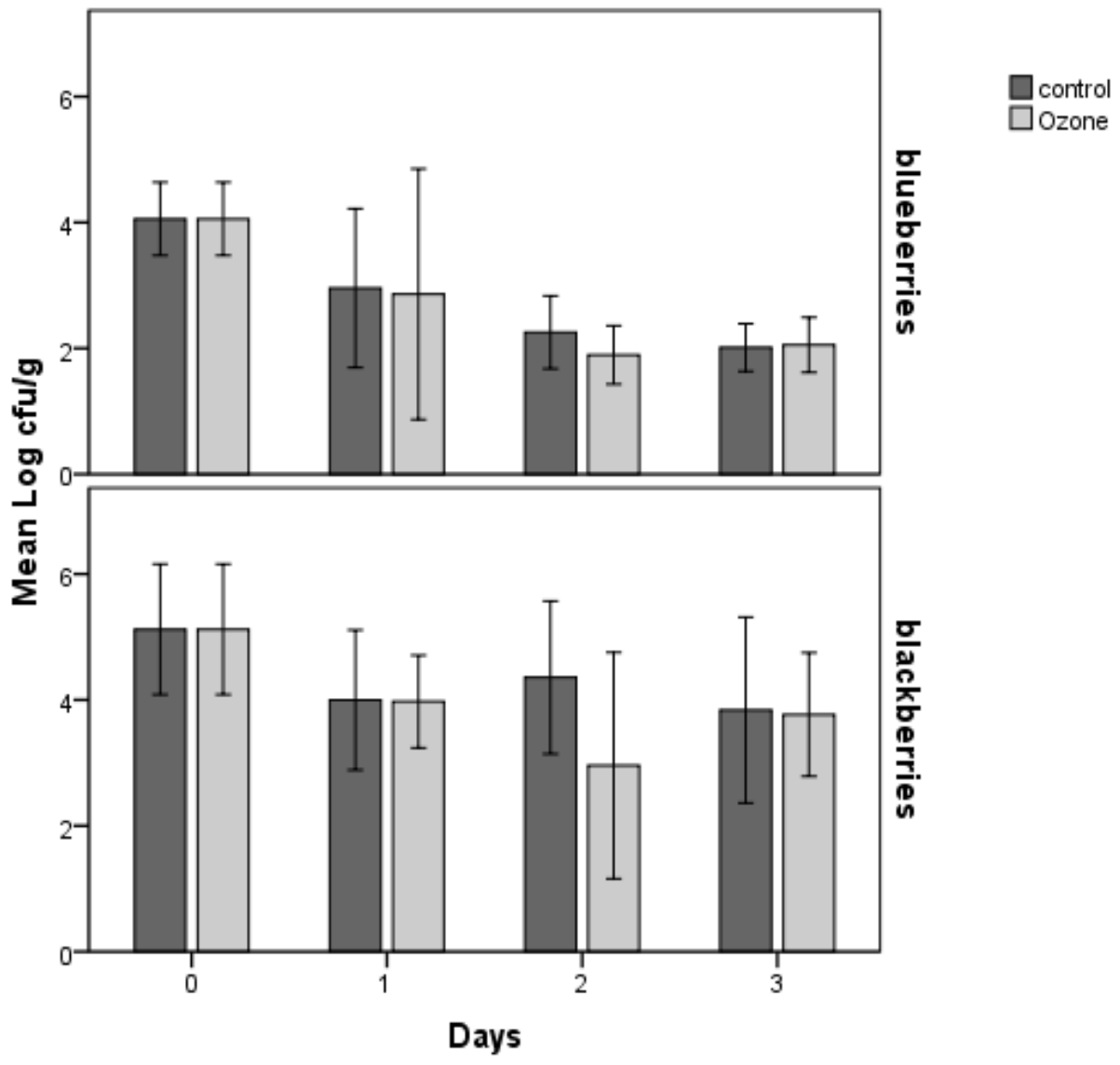

\section{Conclusions:-}

A critical point for the microbiological safetyin the processing line of ready-to-eat vegetables is the washing step. Several studies have investigated the antimicrobial activity of different compounds and have indicated that a log reduction of more than 2.0of naturally present microorganisms is rarely achieved (Tomasoniet al. 2001; Guerzoniet al. 1996; Gras et al. 1994).

Therefore, the observations from the present study are in agreement with the previousstudies that used gaseous ozone as a sanitizer: a 100ppm ozone concentration for 30 minutes resulted in a $1.5 \mathrm{Log}$ reduction in mould on both types of berries and in yeast on blueberries. Similar results were observed forL. innocua and E.coliinoculation of both types of berries.

Storage for three days in refrigerated condition in the presence of $1 \mathrm{ppm}$ of ozone gas resultedin the sanitizationofL.innocua (3Log reduction in blackberries and 1.88Log reduction in blueberries).

Furthermore, because berries are generally not washed and are stored and transported under refrigerated conditions, ozone gastreatment could improve the microbiological quality of fresh blueberries and blackberries. 


\section{References:-}

1. Alwi N.A., Ali A., 2014. Reduction of Escherichia coli O157, Listeria monocytogenes andSalmonella entericasv.Typhimurium population in fresh-cut bell pepper using gaseous ozone. Food Control 46, $304-311$.

2. Barth M.M., Zhou C., Mercier J., Payne F.A., 1995. Ozone Storage Effects on Anthocyanin Content and Fungal Growth in Blackberries. J. Food Sci. 60, 1286-1288.

3. Bermúdez-Aguirre D., Barbosa-Cánovas G.V., 2013. Disinfection of selected vegetables under nonthermal treatments: chlorine, acid citric, ultraviolet light and ozone. Food Contr. 29, 82-89.

4. Concha-Meyer A., Eifert J., Williams R., Marcy J., Welbaum G., 2014. Survival of Listeria Monocytogenes on fresh blueberry (Vacciniumcorymbosum) Stored under Controlled Atmosphere and Ozone. J. Food Protect. 77, 832-836.

5. ECDC, EFSA (EFSA supporting publication- Second update) 2014. Outbreak of hepatitis A in EU/EEU countries. EN-581, 14 pp.

6. EFSA, 2014. Scientific Opinion on the risk posed by pathogens in food of non-animal origin. Part 2 (Salmonella and Norovirus in berries). 12(6), 3706.

7. Fairchild T.M., Foegeding P.M., 1993. A proposed nonpathogenic biological indicator for thermal inactivation of Listeria monocytogenes. Appl. Environ. Microbiol. 59, 1247-1250.

8. Fan L., Song J., McRae K.B., Walker B.A., Sharpe D., 2007. Gaseous ozone treatment inactivates Listeria innocuain vitro. J. Appl. Microbiol. 103, 2657-2663.

9. Gras M., Druet-Michaud C., Cerf O., 1994. La florebactèrienne des feuilles de saladefraìche. Sci. Alim. 14, 173-188.

10. Guerzoni M.E., Gianotti A., Corbo M.R., Sinigaglia M., 1996. Shelf life modelling for fresh-cut vegetables. Posthar. Biolo. Technol. 9, 195-207.

11. Karaka H., Velioglu Y.S., 2007. Ozone applications in fruit and vegetable processing. Food Rev. Int. 23, 91106.

12. Khadre M.A., Yousef A.E. and Kim J.G., 2001. Microbiological Aspects of Ozone Applications in Food: A Review. J. Food Sci. 66, 1242-1252.

13. Kim J.G., Yousef A.E. andKhandre M.A., 2003. Ozone and its current and future application in food industry. Advan. Food Nutr. Res.45, 168-218.

14. Mukherjee A., Speh D., Jones AT., Buesing KM and Diez-Gonzalez F., 2006. Longitudinal microbiological survey of fresh produce grown by farmers in the upper Midwest. J. Food Prot. 69, 1928-1936.

15. Palou L., Crisosto C.H., Smilanick J.L., Adaskaveg J.E., Zoffoli J.P., 2002. Effect of continuous 0.3 ppm ozone exposure on decay development and physiological response on peaches and table grapes in cold storage. Posth. Biol. Technol. 24, 34-48.

16. Palumbo M., Harris L.J., Danyluck M.D., 2013. Survival of foodborne pathogens on berries. Univ. Florida Ins. FoodAgric. Sci. 1-11.

17. Previdi M.P., Franceschini B., Fortini G., 2011. Impiego dell'ozono nel lavaggio e nella sanitizzazione di vegetali freschi destinati alla IV gamma. Ind. Cons. 1, 1-17.

18. Tomasoni L., Previdi M.P., Sansebastiano G., Chiuri A., 2001. Lavaggio e sanitizzazione di verdure destinate alle IV gamma. Ind. Cons. 76, 21-31.

19. Xu Liangji., 1999. Use of Ozone to improve the Safety of Fresh fruits and Vegetables. Food Technol. 53, 58-62. 